\title{
Analisis Tekstur untuk Klasifikasi Motif Kain (Studi Kasus Kain Tenun Nusa Tenggara Timur)
}

\author{
Nicodemus Mardanus Setiohardjo ${ }^{* 1}$, Agus Harjoko ${ }^{2}$ \\ ${ }^{1}$ Jurusan Teknik Elektro, Politeknik Negeri Kupang, Kupang \\ ${ }^{2}$ Jurusan Ilmu Komputer dan Elektronika, FMIPA UGM, Yogyakarta \\ e-mail: *11nicoluck81@gmail.com,, aharjoko@ugm.ac.id
}

\begin{abstract}
Abstrak
Indonesia memiliki banyak kekayaan budaya dalam bentuk kain tradisional, salah satunya kain tenun dari Nusa Tenggara Timur (NTT). Kain tenun dari tiap etnik di NTT memiliki cirikhas motif masing-masing yang merupakan manifestasi kehidupan sehari-hari, kebudayaan dan kepercayaan masyarakat setempat. Di mata pemerhati kain tenun NTT, asal kain tenun dapat diketahui dari motifnya. Tidak semua orang dapat membedakan asal daerah dari motif kain tenun tertentu dikarenakan sulitnya mendefinisikan karakteristik motif kain tenun suatu daerah dan beragamnya motif kain tenun yang ada dan komposisi warna yang beragam pula.

Analisis tekstur adalah teknik analisis citra berdasarkan anggapan bahwa citra dibentuk oleh variasi intensitas piksel, baik citra keabuan maupun warna. Motif kain tenun terbentuk dari variasi intensitas warna sehingga dapat dipandang sebagai tekstur berwarna dari kain tenun. Penelitian ini bertujuan untuk mengetahui diantara pendekatan analisis tekstur menggunakan Gray Level Co-occurrence Matrix (GLCM) yang dikombinasikan dengan momen warna dan pendekatan analisis tekstur menggunakan Color Co-occurrence Matrix (CCM), metode manakah yang memberikan hasil lebih baik untuk klasifikasi motif kain tenun NTT.

Hasil penelitian menunjukkan bahwa untuk klasifikasi motif kain tenun NTT, pendekatan analisis tekstur menggunakan metode CCM memberikan hasil lebih baik dibandingkan pendekatan analisis tekstur menggunakan GLCM yang dikombinasikan dengan momen warna.
\end{abstract}

Kata kunci-klasifikasi citra, GLCM, CCM, momen warna, motif kain tenun NTT

\section{Abstract}

Indonesia have many culture in the form of traditional fabrics, one of them is woven fabric from Nusa Tenggara Timur (NTT). Each NTT ethnic has motif characteristic which ismanifestation of daily life, culture and the faith of local people. For a NTT woven fabric observer, the origin of a woven fabric can be known from the motif. But its difficult to recognising the origin of a woven fabrics because it is hard to define the characteristics of woven fabric motif from a region and wide variety of existing woven fabric motifs and also color composition.

Texture analysis is image analysis technique based on assumption that an image formed by the variation of pixels intensity, both gray and color image. Woven fabric motif formed by the variation of color intensity that can be seen as color texture of the woven fabric. This study aims to determine between texture analysis using GLCM combined with color moment and texture analysis using CCM, which method gives better results for the NTT woven fabric motif classification.

The results showed that for the NTT woven fabric motif classification, texture analysis using CCM gives better results than the texture analysis using GLCM combined with color moment.

Keywords - image classification, GLCM, CCM, color moment, NTT woven fabric motif 


\section{PENDAHULUAN}

$\mathrm{I}$ ndonesia memiliki banyak kekayaan budaya dalam bentuk kain tradisional, seperti songket, batik dan tenun. Salah satu provinsi yang memiliki kain tenun dengan motif yang begitu beragam adalah Nusa Tenggara Timur (NTT). Tiap kesatuan etnik di NTTmemiliki ciri budaya yang diterjemahkan dalam kain tenun tangan tradisional dan menciptakan pola dan motif kain tenun masing-masing yang merupakan manifestasi dari kehidupan sehari-hari, kebudayaan, keadaan alam, dan kepercayaan dari masyarakat setempat.Di mata pemerhati kain tenun NTT, asal sehelai kain tenun dapat diketahui dari motifnya [1]. Namun tidak semua orang dapat membedakan asal daerah dari suatu motif kain tenun tertentu dikarenakan sulitnya mendefinisikan karaktersistik motif kain tenun dari suatu daerah dan begitu beragamnya motif kain tenun yang ada dan dengan komposisi warna yang beragam pula.

Klasifikasi suatu objek dapat dilakukan secara tidak langsung dengan cara melakukan klasifikasi citra objek tersebut berdasarkan fitur-fiturnya. Beberapa fitur yang dapat diekstrak dari sebuah citra adalah warna, bentuk dan tekstur [2].Analisis tekstur adalah salah satu teknik analisis citra berdasarkan anggapan bahwa citra dibentuk oleh variasi intensitas piksel, baik citra keabuan maupun citra warna [3]. Menurut [4] mengatakan bahwa sangat sulit untuk mendefinisikan secara jelas ciri-ciri yang merepresentasikan karakteristik dari tekstur pada suatu citra. Begitu pula dengan kain tenun dari NTT dimana motif kain tenun dari suatu daerah sangat sulit untuk didefinisikan karakteristiknya agar dapat dibedakan dengan motif kain tenun dari daerah lain. Motif ini terbentuk dari variasi intensitas warna sehingga motif kain tenun dapat dipandang sebagai tekstur berwarna dari kain tenun tersebut. Analisis tekstur dilakukan dalam upaya mengekstrak fitur-fitur atau ciri-ciri dari sebuah citra agar dapat dilakukan pengenalan atau pembedaan citra pada suatu kelas dengan citra pada kelas lainnya.

Dalam review yang dilakukan oleh [5] menunjukan bahwa metode statistik orde kedua memberikan hasil yang lebih baik dalam mengesktrak faktor-faktor diskriminan dari sebuah tekstur jika dibandingkan dengan metode spektral dan struktural, dan disebutkan juga bahwa metode statistik orde kedua yang paling populer untuk melakukan analisis tekstur adalah yang dikembangkan oleh [6], yang disebut dengan Gray Level Co-occurrence Matrix(GLCM), bahkan [7] mengatakan bahwa diantara beberapa pendekatan statistik, GLCM terbukti sangat powerful sebagai deskriptor fitur/ciri dalam merepresentasikan karakteristik tekstur dari sebuah citra. Namun begitu GLCM yang bekerja pada domain grayscale memiliki kelemahan yaitu komponen warna dari citra diabaikan sehingga beberapa peneliti mencoba untuk menggabungkan ciri tekstur GLCM dan ciri warna untuk menggambarkan tekstur berwarna dari citra, seperti yang dilakukan oleh [8] dan [9]. Momen warna merepresentasikan ciri warna dari citra secara global, tetapi tidak memberikan informasi spasial dan warna dari piksel-piksel pada citra. Oleh karena itu beberapa peneliti mencoba untuk menerapkan analisis tekstur menggunakan metode GLCM pada citra berwarna, dikenal dengan istilah Color Co-occurrence Matrix (CCM) [10, 11, 12, 13].Penelitian-penelitian tersebut menunjukkan bahwa CCM merepresentasikan warna dan intensitas dari piksel-piksel yang bertetangga pada sebuah citra sehingga CCM dapat digunakan sebagai deskriptor fitur/ciri dalam merepresentasikan karakteristik tekstur berwarna dari sebuah citra.

Berdasarkan uraian tersebut di atas maka pendekatan analisis tekstur dengan ekstraksi ciri statistik orde kedua menggunakan metode GLCM dapat digunakan sebagai deskriptor fitur/ciri untuk melakukan klasifikasi motif kain tenun berdasarkan asal daerah di wilayah NTT. Dalam mengenali asal daerah dari suatu motif kain tenun, unsur warna juga diperhatikan, oleh karena itu perlu digunakan juga ciri warna dalam melakukan klasifikasi motif kain tenun. Namun perlu diteliti, untuk klasifikasi motif kain tenun, metode manakah yang memberikan hasil lebih baik, apakah pendekatan analisis tekstur menggunakan metode GLCM yang dikombinasikan dengan ciri warna ataukah pendekatan analisis tekstur menggunakan metode CCM, yang merupakan penerapan GLCM pada domain warna.

IJCCS Vol. 8, No. 2, July 2014 : $177-188$ 


\section{METODE PENELITIAN}

\subsection{Alat dan Bahan Penelitian}

Bahan penelitian berupa citra kain tenun yang berasal dari 4 pulau di wilayah NTT yang mewakili kelompok etnis di pulau-pulau tersebut, yaitu pulau Timor, Flores, Sabu dan Sumba. Pengambilan gambar kain tenun dilakukan dengan menggunakan perangkat kamera digital dengan kapasitas 12 megapiksel dan jarak pengambilan gambar dari perangkat ke objek kain tenun berjarak 75 centimeter.

Kain tenun pada umumnya berukuran 2 x 1,5 meter dengan rasio 4:3 sehingga dimensi citra kain tenun yang diambil mengikuti rasio tersebut dan difokuskan pada ornamen utama kain tenun yang menonjolkan ciri khas motif kain tenun tersebut. Citra hasil akuisisi dari kamera digital mempunyai ukuran 4000x3000 piksel dan format citra JPG.

Perangkat keras yang digunakan dalam penelitian iniberupa sebuah komputer dengan spesifikasi prosesor Intel Core 2 Duo CPU @ 1.66 GHz dan kapasitas memori sebesar 1 GB.

\section{2Tahapan Pemrosesan Data}

Untuk mendapatkan hasil klasifikasi motif kain tenun berdasarkan analisis tekstur menggunakan metode GLCM yang dikombinasikan dengan momen warna dan analisis tekstur menggunakan metode CCM, data penelitian berupa citra kain tenun perlu melalui serangkaian proses, yaitu pra proses, ekstraksi ciri dan klasifikasi (terdiri dari dua bagian, yaitu proses pembentukan kelas (training) dan proses pengujian (testing)).

\section{2.1Pra Proses}

Pada pra proses, dilakukan pengambilan tiap komponen warna Red (R), Green (G) dan Blue (B) dari citra. Berdasarkan informasi warna Red (R), Green (G) dan Blue (B), kemudian dapat dihitung citra grayscale dengan menggunakan persamaan (1) yang merupakan standar dari PAL dan NTSC. Output dari praproses adalah matriks citra grayscale dan matriks R, G, B dari citra. Tahapan praproses dalam penelitian ini ditunjukkan pada Gambar 1.

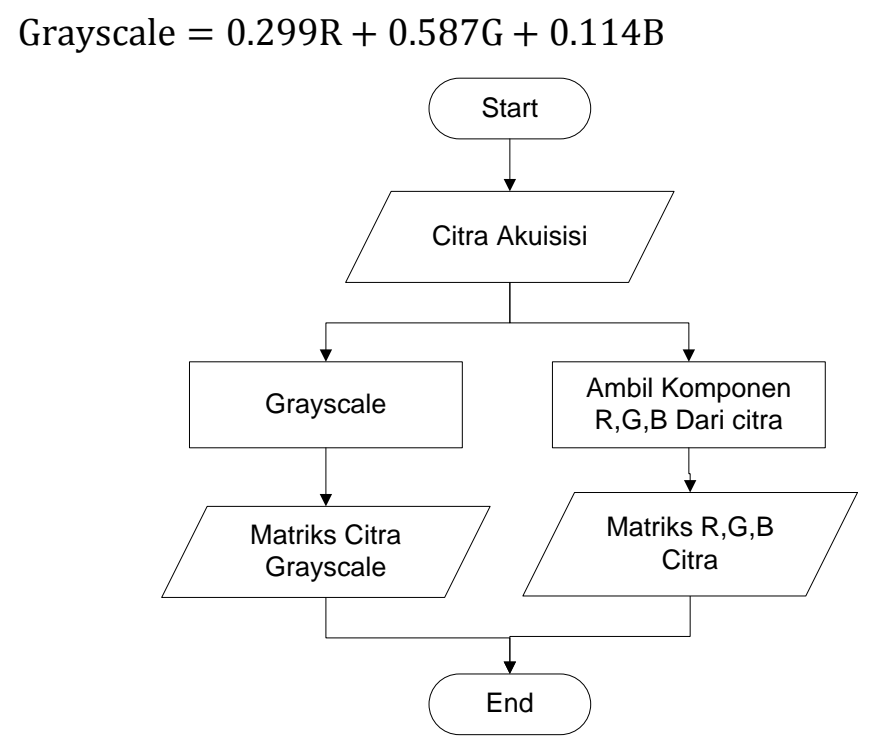

Gambar 1 Tahapan Pra Proses

\section{2.2Ekstraksi Ciri}

Pada penelitian ini terdapat 3 pendekatan ekstraksi ciri yaitu ekstraksi ciri warna menggunakan momen warna, ekstraksi ciri tekstur menggunakan GLCM dan ekstraksi ciri tekstur berwarna menggunakan CCM.Proses ekstraksi ciri ditunjukkan pada Gambar 2. 


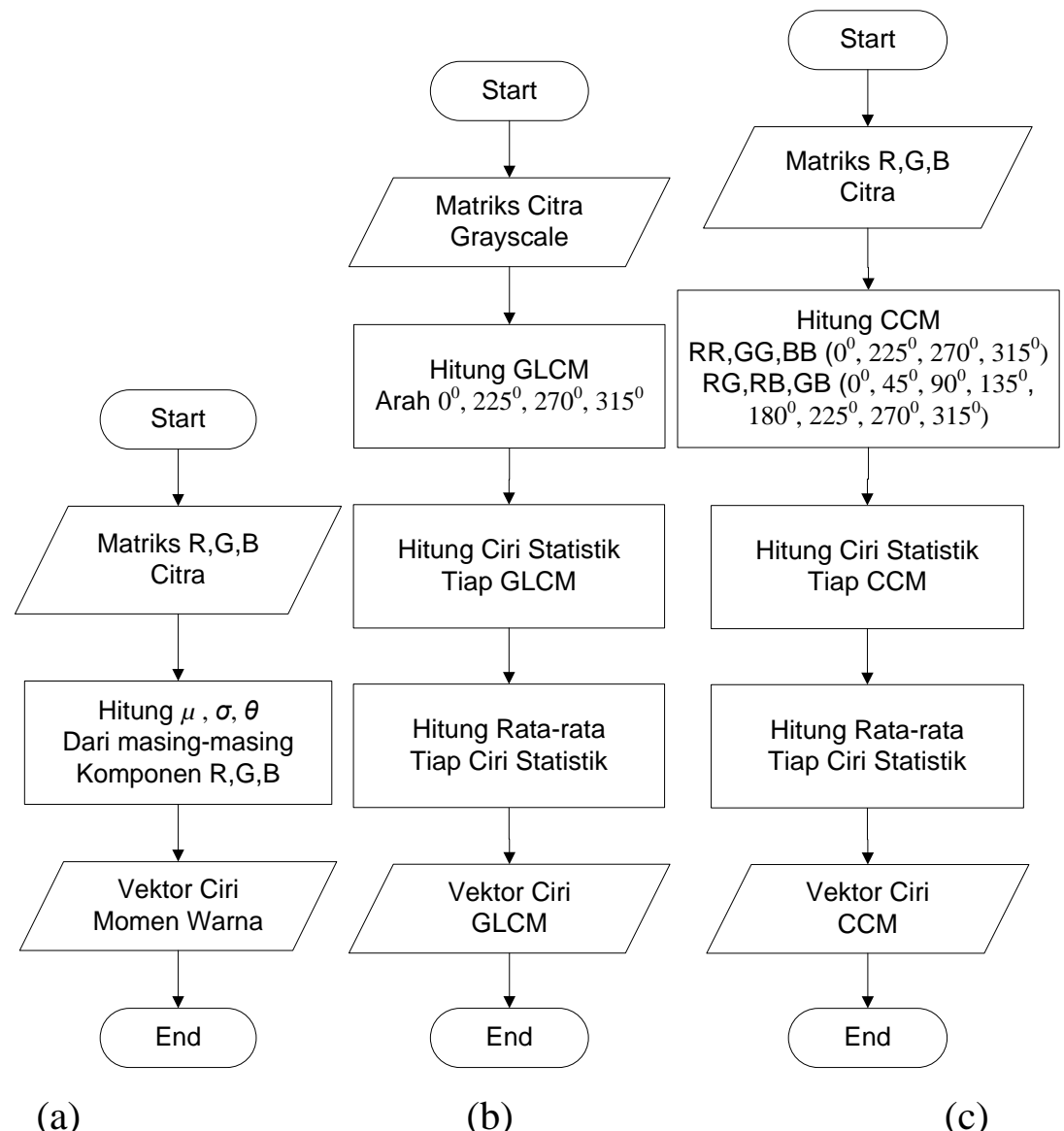

Gambar 2 Proses ekstraksi ciri (a)Momen Warna (b) GLCM (c) CCM

\section{a. Ekstraksi Ciri Momen Warna}

Dari hasil praproses yaitu matriks R, G, B dari citra, kemudian dihitung momen warna pertama $\mu$, persamaan (2) yang mewakili rata-rata warna, momen warna kedua $\sigma$, persamaan (3) merupakan standar deviasi yang menggambarkan keragaman warna dan momen warna ketiga $\theta$, persamaan (4) menggambarkan kecondongan warna [14]. Dengan demikian untuk ciri momen warna didapat 9 ciri, yaitu $\mu R, \sigma R, \theta R, \mu G, \sigma G, \theta G, \mu B, \sigma B$ dan $\theta B$. Proses ekstraksi ciri momen warna dapat dilihat pada Gambar 2(a).

$$
\begin{gathered}
\mu c=\frac{1}{M N} \sum_{i=1}^{M} \sum_{j=1}^{N} p_{i j}^{c} \\
\sigma c=\left[\frac{1}{M N} \sum_{i=1}^{M} \sum_{j=1}^{N}\left(p_{i j}^{c}-\mu c\right)^{2}\right]^{1 / 2} \\
\theta c=\left[\frac{1}{M N} \sum_{i=1}^{M} \sum_{j=1}^{N}\left(p_{i j}^{c}-\mu c\right)^{3}\right]^{1 / 3}
\end{gathered}
$$


Dimana $p_{i j}^{c}$ adalah nilai komponen warna $c$ (Red, Green dan Blue, RGB) pada piksel warna baris ke $i$ dan kolom ke $j$ dari citra. Sedangkan M dan $N$ adalah ukuran panjang dan tinggi dari citra.

\section{b. Ekstraksi Ciri GLCM}

Dari hasil praproses yaitu matriks citra grayscale, kemudian dibentuk matriks kookurensi (GLCM).GLCM yang dibentuk pada penelitian ini menggunakan hubungan ketetanggaan piksel dengan jarak $d=1$. Untuk menghasilkan matriks yang simetris maka matriks ko-okurensi dijumlahkan dengan matriks transpose-nya [6]. Dengan demikian GLCM untuk arah $0^{\circ}$ akan berisi informasi yang sama dengan GLCM $180^{\circ}$, begitu pula GLCM $45^{\circ}$ dan $225^{\circ}$, GLCM $90^{\circ}$ dan $270^{\circ}$, serta GLCM $135^{\circ}$ dan $315^{\circ}$. Oleh karena itu, pada penelitian ini GLCM yang dibentuk hanya 4 arah, yaitu pada arah $0^{0}, 225^{\circ}, 270^{\circ}, 315^{\circ}$.

Setelah semua GLCM terbentuk langkah selanjutnya adalah proses ekstraksi ciri, yaitudengan menghitung empat ciri statistik dari setiap GLCM yang terbentuk (GLCM arah $0^{\circ}$, $225^{\circ}, 270^{\circ}, 315^{\circ}$ ). Empat ciri statistik tersebut adalah energi persamaan (5) untuk mengukur konsentrasi pasangan intensitas pada matriks ko-okurensi, entropi persamaan (6) untuk mengukur keteracakan dari distribusi intensitas, kontras persamaan (7) untuk mengukur kekuatan perbedaan intensitas dalam citra, dan homogenitas persamaan (8) untuk mengukur kehomogenan variasi intensitas citra[6, 15]. Setelah mendapatkan empat ciri statistik dari setiap GLCM, maka langkah selanjutnya adalah menghitung rata-rata tiap ciri statistik dari semua GLCM. Output dari proses ekstraksi ciri GLCM adalah vektor ciri GLCM yang terdiri dari energi, entropi, kontras dan homogenitas.Proses ekstraksi ciri GLCM dapat dilihat pada Gambar 2(b).

$$
\begin{gathered}
\text { Energi }=\sum_{i=1}^{K} \sum_{j=1}^{K} p_{i j}^{2} \\
\text { Entropi }=-\sum_{i=1}^{K} \sum_{j=1}^{K} p_{i j} \log _{2} p_{i j} \\
\text { Kontras }=\sum_{i=1}^{K} \sum_{j=1}^{K}(i-j)^{2} p_{i j} \\
\text { Homogenitas }=\sum_{i=1}^{K} \sum_{j=1}^{K} \frac{p_{i j}}{1+|i-j|}
\end{gathered}
$$

Dimana notasi $p$ melambangkan probabilitas yang bernilai nol hingga satu, yaitu elemen dalam matriks ko-okurensi, $i$ dan $j$ melambangkan pasangan intensitas yang berdekatan, yang dalam matriks ko-okurensi masing-masing menjadi nomor baris dan nomor kolom, sedangkan $K$ merupakan jumlah baris (atau kolom) dari matriks ko-okurensi yang berbentuk matriks bujur sangkar.

\section{c. Ekstraksi Ciri CCM}

Proses ekstraksi ciri CCM pada prinsipnya sama dengan proses ekstraksi ciri GLCM. Perbedaannya adalah CCM dilakukan pada komponen warna $\mathrm{R}, \mathrm{G}$ dan $\mathrm{B}$, sehingga langkah awal dari proses ini adalah dari hasil praproses yaitu matriks R, G, B dari citra, kemudian dibentuk matriks ko-okurensi untuk pasangan warna RR, GG, BB, RG, RB dan GB. Pada pasangan warna RR, GG dan BB yang notabene adalah GLCM pada masing-masing komponen 
warna $\mathrm{R}, \mathrm{G}$ dan $\mathrm{B}$ maka proses pembentukannya sama persis pada proses pembentukan GLCM yaitu hanya pada 4 arah $\left(0^{\circ}, 225^{\circ}, 270^{\circ}, 315^{\circ}\right)$, sedangkan pada pasangan warna $R G, R B$ dan GB tidak hanya dilakukan pada 4 arah tersebut saja tetapi pada 8 arah. Pertimbangannya adalah bahwa matriks ko-okurensi RG, RB dan GB pada arah $180^{\circ}, 45^{\circ}, 90^{\circ}$ dan $135^{\circ}$ akan mewakili matriks ko-okurensi GR, BR dan BG pada arah $0^{\circ}, 225^{\circ}, 270^{\circ}$ dan $315^{\circ}$ sehingga tidak perlu lagi untuk membentuk matriks ko-okurensi untuk pasangan warna GR, BR dan BG.

Setelah semua matriks ko-okurensi terbentuk untuk pasangan warna RR, GG, BB, RG, RB dan GB, langkah selanjutnya adalah proses ekstraksi ciri, yaitu dengan menghitung empat ciri statistik (energi, entropi, kontras dan homogenitas) dari setiap matriks ko-okurensi yang terbentuk dan kemudian menghitung rata-ratanya. Dengan demikian dari proses ekstraksi ciri CCM diperoleh 24 ciri yang kemudian akan digunakan pada proses klasifikasi. Proses ekstraksi ciri CCM dapat dilihat pada Gambar 2 (c).

\section{2.3 Klasifikasi}

Pada proses klasifikasi dibagi menjadi dua bagian, yaitu proses pembentukan kelas dan pengujian klasifikasi.

\section{a. Proses Pembentukan Kelas}

Proses pembentukan kelas dilakukan dengan cara tiap data latih pada tiap kelas dilakukan pra proses dan ekstraksi ciri momen warna, GLCM dan CCM. Vektor ciri momen warna ( 9 ciri, yaitu $\mu R, \sigma R, \theta R, \mu G, \sigma G, \theta G, \mu B, \sigma B$ dan $\theta B$ ) dan vektor ciri GLCM (4 ciri, yaitu energi, entropi, kontras dan homogenitas) disimpan pada sebuah file dengan format CSV (Comma Separated Value), sedangkan vektor ciri CCM (24 ciri, yaitu energi, entropi, kontras dan homogenitas untuk 6 pasangan warna (RR, GG, BB, RG, RB dan GB)) disimpan pada file CSV yang lainnya, sehingga tiap kelas mempunyai 2 buah file CSV. Proses ini dilakukan untuk tiap data latih pada masing-masing kelas.Gambar 3 menunjukkan proses pembentukan kelas.

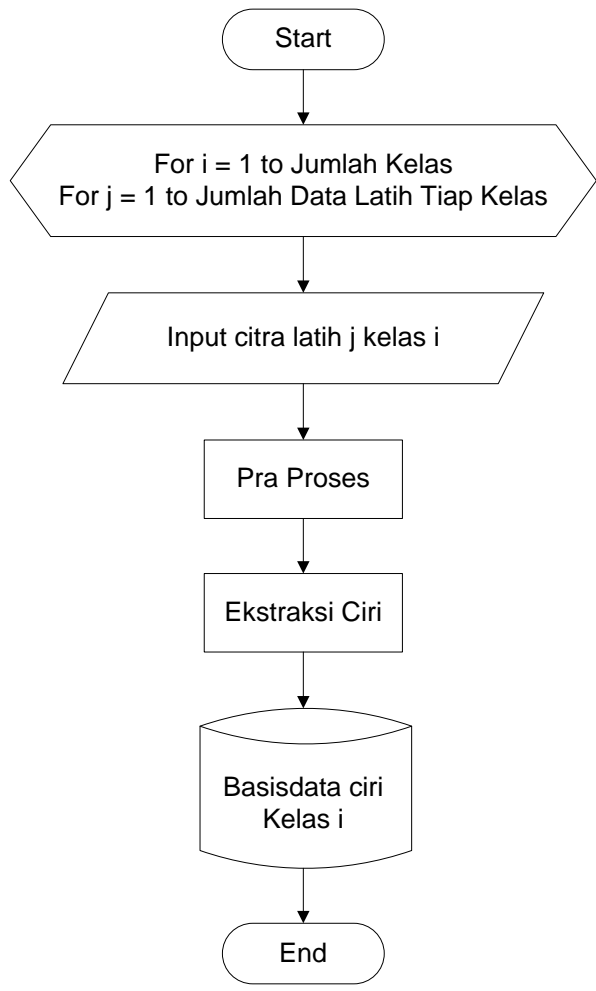

Gambar 3 Proses Pembentukan Kelas 


\section{b. Pengujian Klasifikasi}

Pengujian klasifikasi dimulai dari proses ekstraksi ciri momen warna, GLCM dan CCM dari citra uji. Kemudian dilanjutkan dengan proses pengambilan ciri citra latih dari basisdata ciri. Langkah selanjutnya terbagi menjadi dua bagian, yaitu pengujian dengan menggunakan metode klasifikasi Nearest Mean Classifier (NMC) dan pengujian dengan menggunakan metode klasifikasi K-Nearest Neighbours (KNN).Gambar 4 menunjukkan proses pengujian klasifikasi.

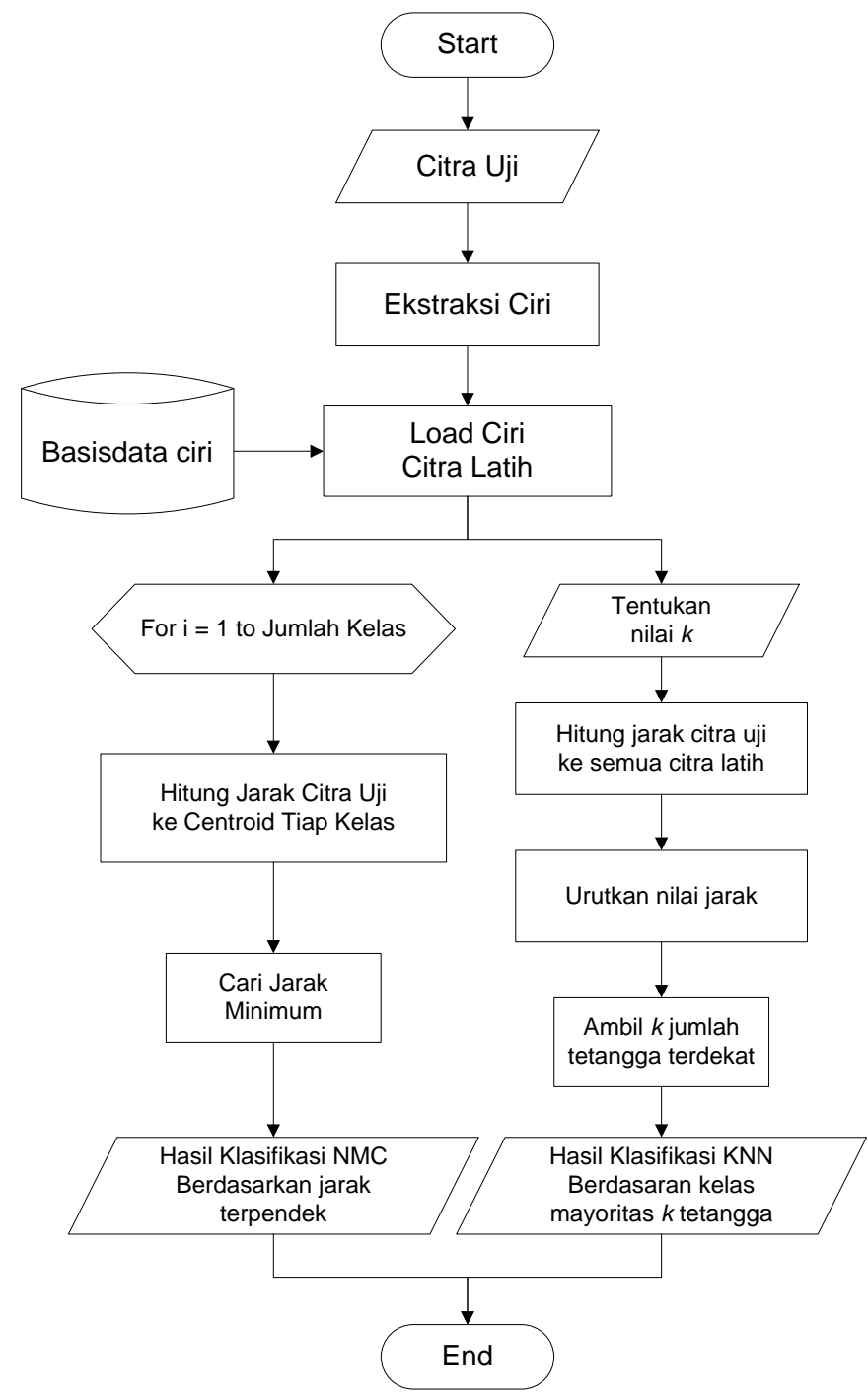

Gambar 4 Proses Pengujian Klasifikasi

Pengujian dengan metode klasifikasi NMC dilakukan dengan menghitung jarak vektor ciri citra uji ke vektor ciri centroid setiap kelas dengan menggunakan ukuran jarak Euclidean distance persamaan (9). Klasifikasi NMC didasarkan atas jarak terdekat vektor ciri citra uji dengan vektor ciri centroid tiap kelas. Hasil yang didapat adalah hasil pengujian dengan metode klasifikasi NMC berdasarkan kombinasi ciri momen warna dan GLCM serta hasil pengujian dengan metode klasifikasi NMC berdasarkan ciri CCM.

Untuk pengujian dengan metode klasifikasi KNN, dimulai dengan menentukan nilai $k$. Langkah selanjutnya adalah menghitung jarak vektor ciri citra uji ke vektor ciri setiap citra latih dengan menggunakan ukuran jarak Euclidean distance persamaan (9). Setelah itu urutkan nilai jarak dari citra uji ke setiap citra latih. Setelah diperoleh $k$ tetangga terdekat, prediksi kelas dari citra uji akan ditentukan berdasarkan kelas mayoritas $k$ tetangga terdekat tersebut. Hasil yang didapat adalah hasil pengujian dengan metode klasifikasi KNN berdasarkan kombinasi ciri 
momen warna dan GLCM serta hasil pengujian dengan metode klasifikasi KNN berdasarkan ciri CCM.

$$
D(x, y)=\sqrt{\sum_{i=1}^{n}\left(x_{i}-y_{i}\right)^{2}}
$$

Dimana $D(x, y)$ adalah jarak dari kedua vektor $x$ dan $y$ dari matrik dengan ukuran $n$ dimensi.

\section{3Pengujian Hasil Klasifikasi}

Pengujian dilakukan untuk mengetahui hasil klasifikasi motif kain tenun Nusa Tenggara Timur berdasarkan analisis tekstur menggunakan metode GLCM yang dikombinasikan dengan momen warna dan berdasarkan analisis tekstur menggunakan metode CCM. Ada empat skenario pengujian, yaitu pengujian hasil klasifikasi berdasarkan :

a. Kombinasi GLCM - momen warna dengan metode klasifikasi NMC.

b. CCM dengan metode klasifikasi NMC.

c. Kombinasi GLCM - momen warna dengan metode klasifikasi KNN.

d. CCM dengan metode klasifikasi KNN.

Untuk mengetahui hasil klasifikasi motif kain tenun, maka dilakukan pengujian dengan menggunakan confusion matrix. Confusion matrix membandingkan kategori per kategori (kelas per kelas) hubungan antara data sebenarnya (Referece Class) atau data lapangan dengan data hasil klasifikasi (Mapped Class). Seperti matriks yang berbentuk bujur sangkar, dengan jumlah kolom dan jumlah baris merupakan jumlah kategori atau kelas yang hasil klasifikasinya akan diestimasi. Seluruh elemen matriks pada diagonal utama merepresentasikan klasifikasi yang benar. Sementara seluruh elemen matriks di luar diagonal utama merepresentasikan kesalahan klasifikasi, yang dibagi menjadi dua kategori yaitu kesalahan omisi (ekslusi), berhubungan dengan elemen-elemen kolom di luar diagonal utama, dan kesalahan komisi (inklusi), berhubungan dengan elemen-elemen baris di luar diagonal utama [16]. Confusion matrix hasil klasifikasi diperlihatkan pada Tabel 1.

Tabel 1 Confusion Matrix [17]

\begin{tabular}{|c|c|c|c|c|c|c|}
\hline & \multicolumn{4}{|c|}{ Data Sebenarnya (Reference Class) } & \multirow{2}{*}{$\begin{array}{l}\text { Total } \\
\mathrm{X}_{\mathrm{i}+}\end{array}$} \\
\hline & & 1 & 2 & $\ldots$ & $q$ & \\
\hline \multirow{4}{*}{$\begin{array}{l}\text { Hasil } \\
\text { Klasifikasi } \\
\text { (Mapped } \\
\text { Class) }\end{array}$} & 1 & $\mathrm{X}_{11}$ & $\mathrm{X}_{12}$ & $\ldots$ & $X_{1 q}$ & $\mathrm{X}_{1+}$ \\
\hline & 2 & $\mathrm{X}_{21}$ & $\mathrm{X}_{22}$ & $\ldots$ & $\mathrm{X}_{2 \mathrm{q}}$ & $\mathrm{X}_{2+}$ \\
\hline & $\ldots$ & $\ldots$ & $\ldots$ & $\ldots$ & $\ldots$ & $\ldots$ \\
\hline & $\mathrm{q}$ & $\mathrm{X}_{\mathrm{q} 1}$ & $\mathrm{x}_{\mathrm{q} 2}$ & $\ldots$ & $\mathrm{X}_{\mathrm{qq}}$ & $\mathrm{X}_{\mathrm{q}+}$ \\
\hline \multicolumn{2}{|l|}{ Total $x_{+j}$} & $\mathrm{X}_{+1}$ & $\mathrm{X}_{+2}$ & $\ldots$ & $\mathrm{X}_{+\mathrm{q}}$ & $\mathrm{n}$ \\
\hline
\end{tabular}

Dimana:

q : banyaknya kelas.

n : total jumlah observasi (jumlah data).

$\mathrm{x}_{\mathrm{ij}}$ : jumlah data pada baris $\mathrm{i}$ kolom $\mathrm{j}$ yang menunjukkan jumlah data kelas $\mathrm{j}$ yang diklasifikasikan sebagai kelas i.

$\mathrm{x}_{\mathrm{i}_{+}}$: jumlah data yang diklasifikasikan sebagai kelas i persamaan (10).

$\mathrm{x}_{+\mathrm{j}}$ : jumlah data sebenarnya pada kelas j persamaan (11).

$$
x_{i+}=\sum_{j=1}^{q} x_{i j}
$$




$$
x_{+j}=\sum_{i=1}^{q} x_{i j}
$$

Penentuan akurasi hasil klasifikasi (menggunakan confusion matrix) untuk setiap kelas dibagi ke dalam dua kelompok, yaitu Producer's Accuracy dan User's Accuracy. Producer's Accuracy persamaan (12) mengindikasikan bagaimana training set dari suatu kelas diklasifikasikan, atau proporsi (rasio) kelas yang terklasifikasikan terhadap kelas (data) yang sebenarnya di lapangan. Sedangkan User's Accuracy persamaan (14) menginidkasikan kebenaran kuantitatif setiap kelas dalam peta tematik hasil klasifikasi dengan kelas (data) sebenarnya di lapangan (reference class).

$$
\begin{aligned}
& O_{j}=x_{j j} / x_{+j} \\
& \bar{O}_{j}=1-O_{j} \\
& C_{i}=x_{i i} / x_{i+} \\
& \bar{C}_{i}=1-C_{i}
\end{aligned}
$$

Omission error (kebalikan Producer's Accuracy) menyatakan kuantitas atau persentasi suatu kelas yang ada di lapangan tetapi tidak terklasifikasikan sebagai kelas itu (ditunjukkan oleh persamaan (13). Commission Error (kebalikan User's Accuracy) menyatakan persentasi suatu atau beberapa kelas lain yang ikut terpetakan sebagai kelas tertentu yang sebenarnya bukan merupakan kelas itu di lapangan ditunjukkan oleh persamaan (15).

Tingkat akurasi secara keseluruhan (Overall Accuracy) dihitung dengan menggunakan persamaan (16), sedangkan error keseluruhan (Overall Error) dihitung dengan persamaan (17).

$$
\begin{aligned}
& A_{o}=\sum_{i=1}^{q} x_{i i} / n \\
& \bar{A}_{o}=1-A_{o}
\end{aligned}
$$

\section{HASIL DAN PEMBAHASAN}

Tahap pengujian bertujuan untuk mengetahui hasil klasifikasi motif kain tenun Nusa Tenggara Timur berdasarkan analisis tekstur menggunakan metode GLCM yang dikombinasikan dengan momen warna dan berdasarkan analisis tekstur menggunakan metode CCM, dengan menggunakan dua metode klasifikasi, yaitu Nearest Mean Classifier (NMC) dan $K$-Nearest Neighbours (KNN).Pengujian yang dilakukan menggunakan dua jenis ukuran citra masukan, yaitu citra berukuran 4000x3000 piksel dan 640x480 piksel. Hal ini dilakukan sebagai perbandingan untuk melihat apakah ada perbedaan yang signifikan antara hasil klasifikasi pada citra dengan ukuran awal 4000x3000 piksel dengan citra masukan yang di-resampling menjadi $640 \times 480$ piksel.Data yang digunakan dalam penelitian ini berjumlah 68 citra terbagi atas dua kelompok data, yaitu: (i) data latih 48 citra (terbagi atas kelas Flores, Timor, Sabu dan Sumba) dan (ii) data uji 20 citra (terbagi atas kelas Flores, Timor, Sabu dan Sumba).

Tabel 2 menggambarkan confusion matrix dari hasil pengujian berdasarkan CCM dengan metode klasifikasi NMC untuk ukuran citra 640x480 piksel.Tiap sel dari confusion matrix terdapat 2 nilai, nilai pertama $\left(x_{\mathrm{ij}}\right)$, pada bagian atas sel, menunjukkan jumlah data kelas $\mathrm{j}$ yang diklasifikasikan sebagai kelas i (i merujuk pada baris dan j merujuk pada kolom), dan nilai kedua $\left(p_{\mathrm{ij}}\right)$, pada bagian bawah sel, menunjukkan proporsi kelas j yang diklasifikasikan sebagai kelas i. Sebagai contoh sel $(1,2)$ dari Tabel 2 nilai pertama $\left(x_{12}\right)$ bernilai 1 , ini berarti bahwa ada 1 data kelas Timor yang diklasifikasikan sebagai kelas Flores, nilai kedua $\left(p_{12}\right)$ bernilai 0.05 
yang didapat dari nilai pertama $\left(x_{12}\right)$ dibagi dengan total jumlah observasi $(1 / 20=0.05)$, ini berarti bahwa 5\% dari total observasi, kelas Timor diklasifikasikan sebagai kelas Flores.

Tabel 2 Confusion Matrix hasil pengujian berdasarkan CCM denganmetode klasifikasi NMC (ukuran citra 640x480 piksel)

\begin{tabular}{|c|c|c|c|c|c|c|c|c|c|}
\hline & \multicolumn{4}{|c|}{ Data Sebenarnya (ReferenceClass) } & \multirow{2}{*}{$\begin{array}{c}\text { Total } \\
x_{\mathrm{i}+} \\
p_{\mathrm{i}+} \\
\end{array}$} & \multirow{2}{*}{$\begin{array}{l}\text { Prod } \\
\text { Acc }\end{array}$} & \multirow{2}{*}{$\begin{array}{l}\text { User } \\
\text { Acc }\end{array}$} & \multirow{2}{*}{$\begin{array}{c}\text { Ovral } \\
\text { Acc }\end{array}$} \\
\hline & & Flores & Timor & Sabu & Sumba & & & & \\
\hline \multirow[b]{2}{*}{$\begin{array}{c}\text { Hasil } \\
\text { Klasifikasi }\end{array}$} & Flores & $\begin{array}{r}4 \\
0.20\end{array}$ & $\begin{array}{r}1 \\
0.05\end{array}$ & $\begin{array}{r}0 \\
0.00\end{array}$ & $\begin{array}{r}1 \\
0.05\end{array}$ & $\begin{array}{r}6 \\
0.30\end{array}$ & 0.80 & 0.67 & \multirow{4}{*}{0.75} \\
\hline & Timor & $\begin{array}{r}0 \\
0.00\end{array}$ & $\begin{array}{r}3 \\
0.15\end{array}$ & $\begin{array}{r}0 \\
0.00\end{array}$ & $\begin{array}{r}0 \\
0.00\end{array}$ & $\begin{array}{r}3 \\
0.15\end{array}$ & 0.60 & 1.00 & \\
\hline \multirow[t]{2}{*}{$\begin{array}{c}\text { (Mapped } \\
\text { Class) }\end{array}$} & Sabu & $\begin{array}{r}0 \\
0.00 \\
\end{array}$ & $\begin{array}{r}1 \\
0.05 \\
\end{array}$ & $\begin{array}{r}4 \\
0.20 \\
\end{array}$ & $\begin{array}{r}0 \\
0.00 \\
\end{array}$ & $\begin{array}{r}5 \\
0.25 \\
\end{array}$ & 0.80 & 0.80 & \\
\hline & Sumba & $\begin{array}{r}1 \\
0.05\end{array}$ & $\begin{array}{r}0 \\
0.00\end{array}$ & $\begin{array}{r}1 \\
0.05\end{array}$ & $\begin{array}{r}4 \\
0.20 \\
\end{array}$ & $\begin{array}{r}6 \\
0.30\end{array}$ & 0.80 & 0.67 & \\
\hline Total & $\begin{array}{l}x_{+\mathrm{j}} \\
p_{+\mathrm{j}} \\
\end{array}$ & $\begin{array}{r}5 \\
0.25 \\
\end{array}$ & $\begin{array}{r}5 \\
0.25 \\
\end{array}$ & $\begin{array}{r}5 \\
0.25 \\
\end{array}$ & $\begin{array}{r}5 \\
0.25 \\
\end{array}$ & $\begin{array}{r}20 \\
1.00 \\
\end{array}$ & & & \\
\hline
\end{tabular}

Total $x_{i+}$ merupakan jumlah data yang diklasifikasikan sebagai kelas $\mathrm{i}$ dan $p_{\text {i+ }}$ merupakan proporsinya. Dari Tabel 2 dapat dilihat bahwa total $x_{1+}$ bernilai 6 dan $p_{1+}$ bernilai 0.30. Ini berarti bahwa jumlah data yang diklasifikasikan sebagai kelas Flores sebanyak 6 kali dengan proporsi sebesar $30 \%$ dari total jumlah observasi. Total $x_{+j}$ merupakan jumlah data sebenarnya pada kelas $\mathrm{j}$ dan $p_{+\mathrm{j}}$ merupakan proporsinya. Untuk penelitian ini jumlah data uji pada tiap kelas diseragamkan yaitu sebesar 5 data.

Dari Tabel 2 terlihat bahwa Producer's Accuracy untuk kelas Flores, Sabu dan Sumba memperoleh nilai tertinggi yaitu 0.80 ini berarti bahwa $80 \%$ dari pengujian terhadap kelas-kelas tersebut diklasifikasikan dengan benar dan 20\% terklasifikasikan sebagai kelas lain. Sedangkan User's Accuracy tertinggi dimiliki oleh kelas Timor dengan nilai 1.00, ini berarti bahwa 100\% dari hasil klasifikasi pada kelas Timor adalah benar kelas Timor, dengan kata lain tidak ada motif tenun dari kelas lain yang diklasifikasikan sebagai kelas Timor.

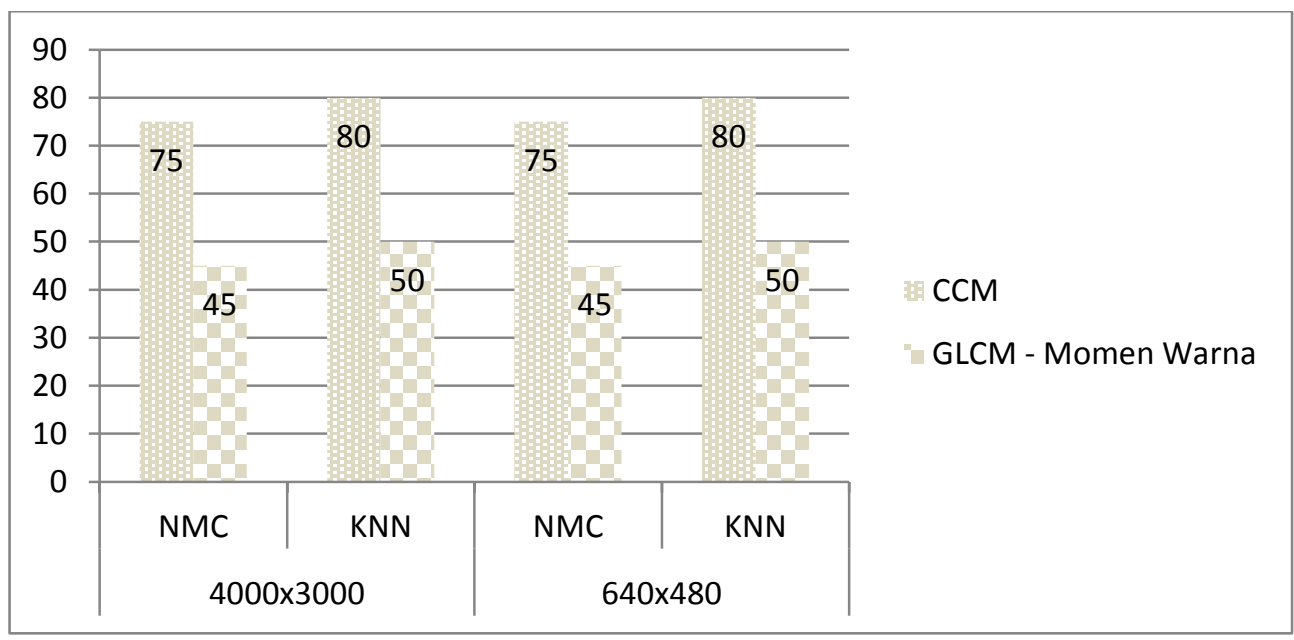

Gambar 5 Grafik Perbandingan Tingkat Akurasi (dalam \%)

Sebagai ringkasan hasil penelitian Gambar 5 memperlihatkan grafik perbandingan tingkat akurasi dari empat skenario pengujian dan juga perbandingan dari penggunaan dua jenis ukuran citra masukan, yaitu citra masukan yang berukuran 4000x3000 piksel dan citra yang diresampling menjadi 640x480 piksel. Dari Gambar 5 terlihat bahwa tidak ada perbedaan antara tingkat akurasi yang dihasilkan dari pengujian dengan menggunakan citra masukan yang berukuran 4000x3000 piksel dan citra yang di-resampling menjadi 640x480 piksel. Dari 
Gambar 5 juga terlihat bahwa hasil klasifikasi motif kain tenun Nusa Tenggara Timur berdasarkan analisis tekstur menggunakan metode CCM dan metode klasifikasi KNN memberikan tingkat akurasi tertinggi yaitu sebesar $80 \%$, sedangkan tingkat akurasi terendah dihasilkan oleh klasifikasi berdasarkan analisis tekstur menggunakan metode GLCM yang dikombinasikan dengan momen warna dan metode klasifikasi NMC, yaitu sebesar $45 \%$.

Tabel 3 Tabel perbandingan waktu komputasi

\begin{tabular}{|l|c|c|c|c|}
\hline \multirow{2}{*}{ Waktu Komputasi } & \multicolumn{2}{|c|}{ Citra 4000x3000 piksel } & \multicolumn{2}{c|}{ Citra 640x480 piksel } \\
\cline { 2 - 5 } & CCM & GLCM-MW & CCM & GLCM-MW \\
\hline Pembentukan Kelas & 6,35 menit & 4,1 menit & 19 detik & 11 detik \\
\hline Klasifikasi & 6,6 detik & 3,65 detik & 378 milidetik & 223 milidetik \\
\hline
\end{tabular}

Tabel 3 merupakan perbandingan waktu komputasi berdasarkan penggunaan metode analisis tekstur yang berbeda (CCM dan kombinasi GLCM dengan momen warna) dan penggunaan citra masukan dengan ukuran yang berbeda (4000x3000 piksel dan 640x480 piksel). Dari Tabel 3 terlihat bahwa pada pengujian yang menggunakan citra masukan berukuran 4000x3000 piksel, waktu komputasi untuk proses pembentukan kelas berdasarkan analisis tekstur GLCM yang dikombinasikan dengan momen warna memiliki waktu yang lebih cepat yaitu 4,1 menit jika dibandingkan dengan metode CCM yang memiliki waktu komputasi 6,35 menit. Untuk proses klasifikasi berdasarkan analisis tekstur GLCM yang dikombinasikan dengan momen warna, waktu komputasi yang dihasilkan adalah 3,65 detik sedangkan waktu komputasi untuk proses klasifikasi berdasarkan analisis tekstur CCM adalah 6,6 detik.

Sementara untuk pengujian yang menggunakan citra masukan berukuran 640x480 piksel, waktu komputasi untuk proses pembentukan kelas berdasarkan analisis tekstur GLCM yang dikombinasikan dengan momen warna memiliki waktu yang lebih cepat yaitu 11 detik jika dibandingkan dengan metode CCM yang memiliki waktu komputasi 19 detik. Untuk proses klasifikasi berdasarkan analisis tekstur GLCM yang dikombinasikan dengan momen warna, waktu komputasi yang dihasilkan adalah 223 milidetik sedangkan waktu komputasi untuk proses klasifikasi berdasarkan analisis tekstur CCM adalah 378 milidetik.

Hasil penelitian secara keseluruhan menunjukkan bahwa untuk klasifikasi motif kain tenun NTT yang mempertimbangkan faktor corak/motif dan warna, pendekatan analisis tekstur menggunakan metode CCM yang menggabungkan informasi spasial dan warna dari pikselpiksel pada citramemberikan hasil yang lebih baik dibandingkan dengan pendekatan analisis tekstur menggunakan metode GLCM yang dikombinasikan dengan momen warna, dimana momen warna merepresentasikan komponen warna dari citra secara global dan GLCM memberikan informasi spasial dari piksel-piksel pada citra grayscale.

Penggunaan citra masukan yang di-resampling menjadi ukuran 640x480 piksel dapat memberikan tingkat akurasi yang relatif sama dengan penggunaan citra masukan awal yang berukuran $4000 x 3000$ piksel. Sementara waktu komputasi yang dihasilkan dari penggunaan citra masukan yang di-resampling menjadi ukuran 640x480 piksel memiliki waktu yang lebih cepat dan menunjukkan perbedaan yang signifikan dibanding dengan waktu komputasi yang dihasilkan oleh penggunaan citra masukan yang berukuran 4000x3000 piksel.

\section{KESIMPULAN}

Berdasarkan hasil penelitian dapat ditarik kesimpulan bahwa untuk klasifikasi motif kain tenun Nusa Tenggara Timur, pendekatan analisis tekstur menggunakan metode CCM secara keseluruhan memberikan hasil yang lebih baik jika dibandingkan dengan pendekatan analisis tekstur menggunakan metode GLCM yang dikombinasikan dengan momen warna. 
Penggunaan citra masukan yang di-resampling menjadi ukuran 640x480 tetap dapat memberikan tingkat akurasi yang relatif samadan memiliki waktu komputasi yang lebih cepat dibandingkan dengan penggunaan citra masukan yang berukuran 4000x3000 piksel.

\section{DAFTAR PUSTAKA}

[1]Therik, J.A., 2012, Budaya Tekstil ENTETE - NTT Nusa Tenun Tangan Nusa Tenggara Timur, Dekranasda Kota Kupang, Kupang.

[2]Lu, G., 1999, Multimedia Database Management Systems, Artech House Inc., Norwood.

[3] Wibawanto, H., 2011, Analisis Tekstur untuk Diskriminasi Massa Kistik dan Non Kistik pada Citra Ultrasonografi, Disertasi, Program Pasca Sarjana Fakultas Teknik UGM, Yogyakarta.

[4]Toennies, K.D., 2012, Advances in Computer Vision and Pattern Recognition: Guide to Medical Image Analysis Methods and Algorithms, Springer, London.

[5] Materka, A. dan Strzelecki, M., 1998, Texture Analysis Methods - A Review, Technical University of Lods, Institute of Electronics, Poland

[6] Haralick, R.M., Shanmugam, K. dan Dinstein, I., 1973, Textural Features for Image Classification, IEEE Trans. On Systems, Man And Cybernetics, Vol. SMC-3, No. 6, pp. 610621.

[7] Siqueira, F.R., Schwartz, W.R. dan Pedrini, H., 2013, Multi-Scale Gray Level CoOccurrence Matrices for Texture Description, Neurocomputing, ISSN 0925-2312, Vol. 120, pp. 336-345.

[8] Kusrini, Hartati, S., Wardoyo, R. dan Harjoko, A., 2008, Klasifikasi Citra Dengan Pohon Keputusan, JUTI, Vol. 7, No. 2, pp. 49-58.

[9] Maheshwary, P. dan Sricastava, N., 2009, Prototype System for Retrieval of Remote Sensing Images based on Color Moment and Gray Level Co-Occurrence Matrix, IJCSI, Vol. 3, pp. 20-23.

[10] Drimbarean, A. dan Whelan, P.F., 2001, Experiments in Colour Texture Analysis, Pattern Recognition Letters, Vol. 22, pp. 1161-1167.

[11] Shim, S. dan Choi, T.S., 2003, Image Indexing by Modified Color Co-occurrence Matrix, IEEE International Conference on Image Processing, Vol. 3, pp. 493-496.

[12] Arvis, V., Debain, C., Berducat, M. dan Benassi, A., 2004, Generalization of The Cooccurrence Matrix For Colour Images: Application To Colour Texture Classification, Image Anal Stereol, Vol. 23, pp. 63-72.

[13] Liang, D. dan Lam, E.Y., 2006, Image Indexing Using Weighted Color Co-occurrence Matrix and Feature Selection, IEEE Region 10 Conference, TENCON 2006, 14-17 November 2006, pp. 1-4.

[14] Acharya, T. dan Ray, A.K., 2005, Image Processing: Principles and Applications, John Wiley and Sons Inc., New Jersey.

[15] Gonzalez, R.C. dan Woods, R.E., 2008, Digital Image Processing, Third Ed., Pearson Education, New Jersey.

[16] Rossiter, D.G., 2004, Technical Note: Statistical Methods for Accuracy Assesment of Classified Thematic Maps, Depertment of Earth Systems Analysis, International Institute for Geo-information Science and Earth Obserbation (ITC), Enschede.

[17] Stehman, S.V. dan Czaplewski, R.L., 1998, Design and Analysis for Thematic Map Accuracy Assessment: Fundamental Principles, Remote Sensing of Environment, Vol. 64, pp. 331-344.

IJCCS Vol. 8, No. 2, July 2014 : $177-188$ 